\title{
Determination of the absolute configuration of the novel anti-trypanosomal iridoid molucidin isolated from Morinda lucida by X-ray analysis
}

\author{
Satoru Karasawa ${ }^{1}$, Kenji Yoza ${ }^{2}$, Nguyen Huu Tung ${ }^{3,4}$, Takuhiro Uto ${ }^{3}$, Osamu Morinaga ${ }^{3}$, Mitsuko \\ Suzuki $^{5,6}$, Kofi D. Kwofie ${ }^{5}$, Michael Amoa-Bosompem ${ }^{5}$, Daniel A. Boakye ${ }^{5}$, Irene Ayi ${ }^{5}$, Richard Adegle ${ }^{7}$, \\ Maxwell Sakyiamah $^{7}$, Frederick Ayertey ${ }^{7}$, Frederic Aboagye ${ }^{7}$, Alfred A. Appiah ${ }^{7}$, Kofi B-A Owusu ${ }^{5}$, Isaac \\ Tuffour ${ }^{5}$, Philip Atchoglo 5 , Kwadwo K. Frempong ${ }^{5}$, William K. Anyan ${ }^{5}$, Regina Appiah-Opong ${ }^{5}$, \\ Alexander K. Nyarko ${ }^{5}$, Taizo Yamashita ${ }^{3}$, Yasuchika Yamaguchi ${ }^{3}$, Dominic Edoh ${ }^{7}$, Kwadwo Koram ${ }^{5}$, \\ Shoji Yamaoka ${ }^{6}$, Nobuo Ohta ${ }^{6}$, Yukihiro Shoyama ${ }^{4}$ \\ ${ }^{1}$ Graduate School of Pharmaceutical Sciences, Kyushu University, 3-1-1 Maidashi, Higashi-ku, Fukuoka, $812-8582$ Japan \\ ${ }^{2}$ Bruker AXS K. K., Yokohama, Kanagawa 221-0022, Japan \\ ${ }^{3}$ Faculty of Pharmaceutical Sciences, Nagasaki International University, 2825-7 Huis Ten Bosch, Sasebo, Nagasaki 859-3298, Japan \\ ${ }^{4}$ School of Medicine and Pharmacy, Vietnam National University, Hanoi, 144 Xuan Thuy St., Cau Giay, Hanoi, Vietnam \\ ${ }^{5}$ Noguchi Memorial Institute for Medical Research, University of Ghana, Legon LG 581, Ghana \\ ${ }^{6}$ Faculty of Medicine, Tokyo Medical and Dental University, 1-5-45 Yushima, Bunkyo-ku, Tokyo 113-8510, Japan \\ ${ }^{7}$ Centre for Scientific Research into Plant Medicine, Mampong - Akuapem 73, Ghana
}

\section{ARTICLE INFO}

Article history:

Received

Received in revised form

Accepted

Available online

Keywords:

Morinda lucida

Rubiaceae

Molucidin

Anti-trypanosomal activity

$\mathrm{X}$-ray analysis

Absolute configuration

\section{ABSTRACT}

\begin{abstract}
The strong anti-trypanosomal active compound, molucidin, contains a spirolactone tetracyclic iridoid skeleton and is isolated from Morinda lucida as an enantiomer of oruwacin, which is isolated from the same plant. To confirm the absolute configuration of molucidin, we prepared single crystals of molucidin for X-ray analysis. The absolute configuration of the afforded single crystal was determined by $\mathrm{X}$-ray crystallography using a $\mathrm{Cu}$ radiation source. The X-ray diffraction data were collected at $93 \mathrm{~K}$ in the $2 \theta$ range $7.468^{\circ}-134.99^{\circ}$ and analyzed using the SHELXL-2014 program. The corresponding chiral quaternary carbon atoms in molucidin were unambiguously determined as $1 R, 5 S, 8 S, 9 S$, and $10 S$. Notably, both enantiomers of a single moleucle, molucidin and oruwacin, with a rigid structure have been isolated from the same plant species. The biosynthetic pathway for formation of molucidin is also discussed on the basis of the absolute configuration. Our results for the first time support for structural elucidation of tetracyclic iridoids using X-ray analysis.
\end{abstract}

2009 Elsevier Ltd. All rights reserved.

\section{Introduction}

Recently, the use of medicinal plants has garnered the attention of researchers widely. ${ }^{1,2}$ Morinda lucida Benth. (Rubiaceae), medium-sized evergreen trees with dark-shiny leaves on the upper surface, is a well-known medicinal plant widely distributed in Africa. ${ }^{3}$ Researchers found that M. lucida is a natural resource rich in antraquinones similar to oruwal, 3hydroxyanthraquinone-2-carboxyaldehyde, 1,3-dihydroxy-2methylanthraquinone, 1,3-dihydroxyanthraquinone-2carboxyaldehyde, and so on. ${ }^{4-7}$ Furthermore, various iridoids have been isolated from Morinda spp. and other members from the Rubiaceae family. The tetracyclic spirolactone iridoids including oruwacin (from M. lucida) and prismatomerin (from Prismatomeris tetrandra) have been found to be relatively rare and possess unique rigid structures. ${ }^{8-11}$ The structural identification of these analogs, especially the assignment of the absolute configuration, has been debated in the literature. ${ }^{9,12-14}$
Very recently, the unambiguous absolute configuration of the tetracyclic iridoids, plumericin, isoplumericin, oruwacin, and prismatomerin was confirmed. ${ }^{12-14}$

In our ongoing study on extracting anti-trypanosomal active compounds from Ghanaian medicinal plants, we isolated the novel anti-trypanosomal iridoid, molucidin (named by our group) from the leaves of $M$. lucida, whose structure was assigned on the basis of physicochemical and spectroscopic studies (NMR and electron capture dissociation (ECD) spectra). ${ }^{15}$ The Cotton effects in the ECD spectrum and the specific rotation were opposite in sign compared with oruwacin, suggesting that the stereochemistry of molucidin is the opposite that of oruwacin. ${ }^{12,15}$ To further confirm the stereochemistry of molucidin, we prepared single crystals of molucidin and analyzed them using Xray diffractometry. This study examined the determination of the absolute configuration of molucidin by X-ray analysis and the relation between molucidin and oruwacin.

* Corresponding author. Tel: +81-956-20-5653; fax: +81-956-20-5653; e-mail: shoyama@niu.ac.jp 


\section{Results and Discussion}

As previously reported, ${ }^{15}$ the structure of molucidin has been elucidated by high-resolution electrospray ionisation mass spectrometry (HR-ESI-MS), NMR spectroscopy, and comprehensive analysis of the HMQC, HMBC, H-H COSY, and NOESY spectra enabled complete assignments of its proton and carbon signals. The relative configuration including the $E$ geometry of C-11-C-13 double bond and the absolute configuration of its spirolactone tetracyclic iridoid skeleton in particular was assigned as $(1 R, 5 S, 8 S, 9 S, 10 S)$ according to the extensive NMR spectra, optical rotation value, and circular dichroism (CD) spectrum. As shown in the CD spectrum, the Cotton effects at $235 \mathrm{~nm}$ (positive) and 250 (negative), which were consistent with the literature, further confirmed the stereochemistry as $(1 R, 5 S, 8 S, 9 S, 10 S)$. Molucidin is (-)oruwacin, which is the enantiomer of oruwacin (Fig. 1). Oruwacin was first isolated by Adesogan ${ }^{10}$ in 1978 from leaves of $M$. lucida. Until recently, its absolute stereochemistry was unambiguously clarified as $(1 S, 5 R, 8 R, 9 R, 10 R)$ by the combination of NMR spectra and optical rotation using computational calculation and experimental value in the literature. $^{12}$

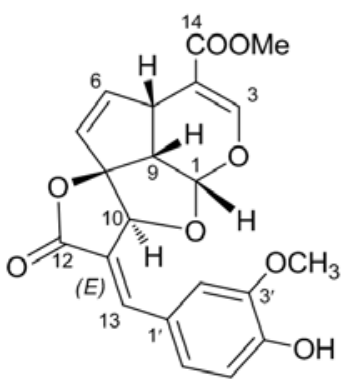

(1R, 5S, 8S, 9S, 10S)

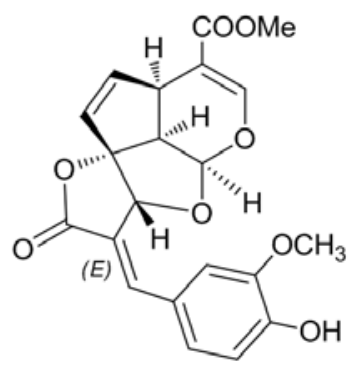

$(1 S, 5 R, 8 R, 9 R, 10 R)$ Oruwacin
Figure 1. The structure of molucidin and oruwacin.

Our further effort resulted in the preparation of single crystals of molucidin for X-ray analysis. Recrystallization of molucidin from a $\mathrm{MeOH}$ solution at room temperature yielded colorless needle-shaped crystals. To reveal the absolute configuration of the afforded single crystal $(0.03 \times 0.04 \times 0.4 \mathrm{~mm})$, X-ray crystallography was performed using a Bruker APEX2 diffractometer with a $\mathrm{Cu}$ radiation source. X-ray diffraction data were collected at $93 \mathrm{~K}$ in the $2 \theta$ range $7.468^{\circ}-134.99^{\circ}$ and analyzed using the SHELXL-2014 program. The unit cell of molucidin was determined to be the orthorhombic chiral space group of $P 2_{1} 2_{1} 2_{1}$ (No. 19) with $Z=4$. The resolved molecular structure had a small Flack parameter (the value of deviation), 0.00 (No. 7), indicating that the corresponding chiral quaternary carbon atoms in molucidin were unambiguously determined and found to be $1 R, 5 S, 8 S, 9 S$, and $10 S .^{16}$ The crystal structure of molucidin is shown in Fig. 2, and the selected crystallographic data are summarized in Table 1.

To the best of our knowledge, this is the first result of crystallization of a tetracyclic iridoid in an orthorhombic space group. Furthermore, single crystal X-ray diffraction using graphite monochromated $\mathrm{CuK \alpha}$ radiation $(\lambda=1.54187 \AA)$ gave an ideal Flack parameter, allowing an unambiguous assignment of the complete absolute configuration of the targeted compound. This study supports the absolute configurations assigned to molucidin and likely those of the tetracyclic iridoid derivatives such as plumericin, isoplumericin, oruwacin, and prismatomerin.

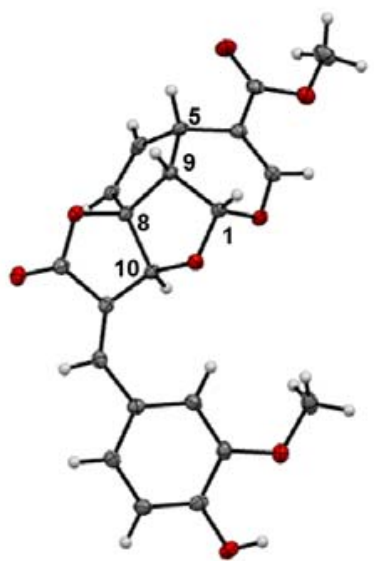

Figure 2. ORTEP drawing (50\% probability) of molecular structure for molucidin. $\mathrm{C}$ and $\mathrm{O}$ atoms are gray and red color, respectively. The chiral quaternary carbon atoms are numbering, respectively.

Table 1. Crystallographic data and structural refinement information for molucidin.

\begin{tabular}{lc}
\hline empirical formula & $\mathrm{C}_{21} \mathrm{H}_{18} \mathrm{O}_{8}$ \\
formula weight & 398.35 \\
crystal system & Orthorhombic \\
space group & $P 2_{1} 2_{1} 2_{1}($ no. 19$)$ \\
$a / \AA$ & $4.68040(10)$ \\
$b / \AA$ & $8.1049(3)$ \\
$c / \AA$ & $47.3450(15)$ \\
$\alpha, \beta, \gamma / \rho$ & 90 \\
$V / \AA^{3}$ & $1795.99(10)$ \\
$\mu / \mathrm{mm}^{-1}$ & 0.965 \\
$Z\left(Z^{\prime}\right)$ & $4(1)$ \\
crystal size/mm & $0.40 \times 0.04 \times 0.03$ \\
$D_{\text {calc }} / \mathrm{gcm}^{-3}$ & 1.473 \\
$F(000)$ & 832 \\
radiation & $\mathrm{CuK \alpha}$ \\
$T / \mathrm{K}$ & 93 \\
no. reflections measured & 13490 \\
no. unique reflections & 3231 \\
no. parameters & 266 \\
$R_{1}(I>2 \sigma(I))^{\mathrm{a}}$ & 0.0323 \\
$w R_{2}($ all data) & $\mathrm{a}$ \\
$\mathrm{GOF}$ & 0.0751 \\
\end{tabular}

Both enantiomers of a particular compound can be separately isolated from different plant species, such as lignans from Arctium lappa ${ }^{17}$ and Forsythia suspense. ${ }^{18}$ Moreover, a set of enantiomers of naphtoquinones, shikonin, and alkannin were isolated from Lithospermum erythrorhizon ${ }^{19}$ and Alkanna tinctoria, respectively. ${ }^{20}$ In a previous study on enzymatical synthesis of enantiomers, we had confirmed that a marihuana compound, cannabichromenic acid, can be biosynthesized from cannabigerolic acid with no asymmetric carbon. In this case, a mixture of enantiomers was obtained because a geranyl group is enzymatically cyclized to prepare a chromen framework, possessing an asymmetric center on flexible carbon. ${ }^{21}$ In contrast, tetrahydrocannabinolic acid has an asymmetric carbon in a cyclic rigid framework that is biosynthesized from the precursor, i.e., cannabigerolic acid, to give a single enantiomer. ${ }^{22,23}$ Regarding the biosynthetic pathway of molucidin, molucidin might be biosynthesized from secologanin which is a common component in Rubiaceae family although it has not been confirmed in $M$. lucida. Secologanin itself may be first deglycosided and recyclized to reveal molucidin, as shown in Fig. 3. During these biosynthetic reactions, the configurations of $\mathrm{C} 1, \mathrm{C} 5$, and $\mathrm{C} 9$ in the molucidin structure are stably maintained similar to those of 


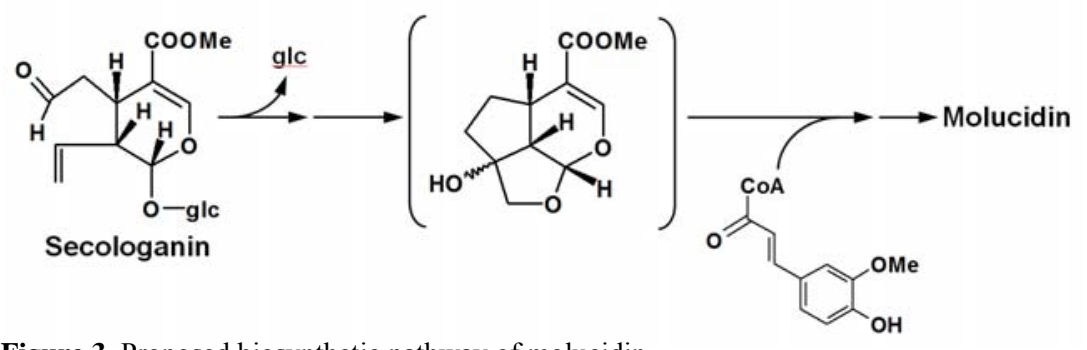

Figure 3. Proposed biosynthetic pathway of molucidin.

iridoids and/or monoterpene iridoid alkaloid until the strictosidine structure, a key precursor for indole alkaloids. ${ }^{24}$ Furthermore, it is remarkable that both enantiomers, molucidin and oruwacin, were isolated from the same plant species, $M$. lucida, although the biosynthetic pathway of both enantiomers might be impossible by the corresponding enzymes.

\section{Materials and Methods}

\subsection{Isolation of molucidin}

Molucidin was isolated from a $\mathrm{CHCl}_{3}$ extract of $M$. lucida leaves, as reported previously. ${ }^{15}$ The structure was confirmed by NMR and mass spectra analysis.

Molucidin: Colorless crystal; $\mathrm{mp} 171-172{ }^{\circ} \mathrm{C} ;[\alpha]_{p}^{25}-188.5^{\circ}(c$ 1.0, $\mathrm{CHCl}_{3}$ ); HR-ESI-MS m/z: $399.1084[\mathrm{M}+\mathrm{H}]^{\dagger}$ (calcd. for $\left.\mathrm{C}_{21} \mathrm{H}_{19} \mathrm{O}_{8}, 399.1080\right)$; $\mathrm{CD} \mathrm{nm}(\Delta \varepsilon)(c 0.1 ; \mathrm{MeOH}): 235$ (1.4), 250 $(-2.7) ;{ }^{1} \mathrm{H}-\mathrm{NMR}\left(\mathrm{CDCl}_{3}, 400 \mathrm{MHz}\right) \delta: 3.58(1 \mathrm{H}, \mathrm{dd}, J=10.0,6.0$ $\mathrm{Hz}, \mathrm{H}-9), 3.78$ (3H, s, 14-COOCH$), 3.96$ (3H, s, 3'-OCH3), 4.05 $(1 \mathrm{H}, \mathrm{dt}, J=10.0,2.0 \mathrm{~Hz}, \mathrm{H}-5), 5.22(1 \mathrm{H}, \mathrm{s}, \mathrm{H}-10), 5.63(1 \mathrm{H}, \mathrm{dd}$, $J=6.4,2.4 \mathrm{~Hz}, \mathrm{H}-7), 5.64(1 \mathrm{H}, \mathrm{d}, J=6.0 \mathrm{~Hz}, \mathrm{H}-1), 6.03(1 \mathrm{H}, \mathrm{dd}$, $J=6.4,2.0 \mathrm{~Hz}, \mathrm{H}-6), 6.99\left(1 \mathrm{H}, \mathrm{d}, J=8.0 \mathrm{~Hz}, \mathrm{H}-5^{\prime}\right), 7.26(1 \mathrm{H}$, dd, $\left.J=8.0,2.0 \mathrm{~Hz}, \mathrm{H}-6^{\prime}\right), 7.43\left(1 \mathrm{H}, \mathrm{d}, J=2.0 \mathrm{~Hz}, \mathrm{H}-2^{\prime}\right), 7.46$ $(1 \mathrm{H}, \mathrm{s}, \mathrm{H}-3), 7.78(1 \mathrm{H}, \mathrm{s}, \mathrm{H}-13)$; and ${ }^{13} \mathrm{C}-\mathrm{NMR}\left(\mathrm{CDCl}_{3}, 100\right.$ MHz) $\delta$ : 102.4 (C-1), 153.0 (C-3), 109.6 (C-4), 38.5 (C-5), 141.1 (C-6), 125.9 (C-7), 104.4 (C-8), 54.3 (C-9), 82.2 (C-10), 120.1 (C-11), 170.0 (C-12), 144.9 (C-13), 166.7 (C-14), 51.7 (14$\left.\mathrm{COOCH}_{3}\right), 126.5\left(\mathrm{C}-1^{\prime}\right), 112.4\left(\mathrm{C}-2^{\prime}\right), 149.1\left(\mathrm{C}-3^{\prime}\right), 147.0\left(\mathrm{C}-4^{\prime}\right)$, $115.1\left(\mathrm{C}-5^{\prime}\right), 125.9\left(\mathrm{C}-6^{\prime}\right), 56.0\left(3^{\prime}-\mathrm{OCH}_{3}\right)$.

\subsection{Single crystal $X$-ray diffraction ( $S X R D)$}

A suitable single crystal of molucidin was glued onto a glass fiber using epoxy resin. X-ray diffraction data were collected on a Bruker APEX-2 diffractometer with graphite monochromated $\mathrm{CuK} \alpha$ radiation $(\lambda=1.54187 \AA)$. Reflections were collected at $93 \pm 1 \mathrm{~K}$. The molecular structures were solved by direct methods (SHELXL-2014) to give a P212121 (No. 19) space group. All nonhydrogen atoms were refined anisotropically and hydrogen atoms were refined isotropically. Crystallographic data collection and structural refinement information for molucidin are listed in Table 1. The Flack parameter value was less than 0.3 , indicating that the absolute configuration was determined correctly. Crystallographic data for the structure reported in this study have been deposited with the Cambridge Crystallographic Data Center as supplementary publication no. CCDC 1419523.

\section{Acknowledgments}

The authors are grateful to Prof. T. Tanaka, Faculty of Pharmaceutical Science, Nagasaki University for CD measurement. This study was supported by Science and Technology Research Partnership for Sustainable Development (SATREPS) Grant from Japan Science and Technology Agency (JST) and Japan International Cooperation Agency (JICA).

\section{References and notes}

1. Konning, G. H.; Agyare, C.; Ennison B. Fitoterapia 2004, 75, 65-67.

2. Fokunang, C. N.; Ndikum, V.; Tabi, O. Y.; Jiofack, R. B.; Ngameni, B.; Guedje, N. M.; Tembe-Fokunang, E. A.; Tomkins, P.; Barkwan, S.; Kechia, F.; Asongalem, E.; Ngoupayou, J.; Torimiro, N. J.; Gonsu, K. H.; Sielinou, V.; Ngadjui, B. T.; Angwafor, F. III; Nkongmeneck, A.; Abena, O. M.; Ngogang, J.; Asonganyi, T.; Colizzi, V.; Lohoue, J.; Kamsu-Kom. Afr. J. Tradit. Complement. Altern. Med. 2011, 8, 284-295.

3. Lawal, H. O.; Etatuvie, S. O.; Fawehinmi, A. B. J. Nat. Prod. 2012, 5, 93-99.

4. Illescas, B. M.; Martin, N. J. Org. Chem. 2000, 65, 5986-5995.

5. Ee, G. C.; Wen, Y. P.; Sukari, M. A.; Go, R.; Lee, H. L. J. Nat. Prod. Res. 2009, 23, 1322-1329.

6. Demagos, G. P.; Baltus, W.; Höfle, G. New anthraquinone and anthraquinone glycosides from Morinda lucida. Z. Naturforsch. 1981, 36, 1180-1184.

7. Adesida, G. A.; Adesogan, E. K. J. Chem. Soc. Chem. Commun. 1972, 1, 405-406.

8. Dinda, B.; Debnath, S.; Harigaya, Y. Chem. Pharm. Bull. 2007, $55,159-222$.

9. Elsasser, B.; Krohn, K.; Akhtar, M. N.; Florke, U.; Kouam, S. F.; Kuigoua, M. G.; Ngadjui, B. T.; Abegaz, B. M.; Antus, S.; Kurtan, T. Chemistry \& Biodiversity 2005, 2, 799-808.

10. Adesogan, E. K. Phytochemistry 1979, 18, 175-176.

11. Krohn, K.; Gehle, D.; Dey, S. K.; Nahar, N.; Mosihuzzaman. M.; Sultana, N.; Sohrab, M. H.; Stephens, P. J.; Pan, J. J.; Sasse, F. J. Nat. Prod. 2007, 70, 1339-1343.

12. Stephens, P. J.; Pan, J. J.; Devlin, F. J.; Cheeseman, J. R. J. Nat. Prod. 2008, 71, 285-288.

13. Stephens, P. J.; Pan, J. J.; Devlin, F. J.; Krohn, K.; Kurtan, T. J. Org. Chem. 2007, 72, 3521-3536.

14. Stephens, P. J.; Pan, J. J.; Krohn, K. J. Org. Chem. 2007, 72, 7641-7649.

15. Suzuki, M.; Tung, N. H.; Kwofie, K. D.; Adegle, R.; AmoaBosompem, M.; Sakyiamah, M.; Ayertey, F.; Owusu, K. B.; Tuffour, I.; Atchoglo, P.; Frempong, K. K.; Anyan, W. K.; Uto, T.; Morinaga, O.; Yamashita, T.; Aboagye, F.; Appiah, A. A.; Appiah-Opong, R.; Nyarko, A. K.; Yamaoka, S.; Yamaguchi, Y.; Edoh, D.; Koram, K.; Ohta, N.; Boakye, D. A.; Ayi, I.; Shoyama, Y. Bioorg. Med. Chem. Lett. 2015, 25, 3030-3033.

16. Flack, H. D. Acta Crystallogr A 1983, 39, 876-881.

17. Suzuki, S.; Umezawa, T.; Shimada, M. Biosci. Biotechnol. Biochem. 2002, 66, 1262-1269.

18. Umezawa, T.; Davin, L. B.; Yamamoto, E.; Kingston, D. G. I.; Lewis, N. G. J. Chem. Soc. Chem. Commun. 1990, 20,1405-1405.

19. Kuroda, C. J. Tokyo Chem. Soc. 1918, 39, 1051-1115.

20. Brockmann, H. Justus. Liebigs. Ann. Chem. 1936, 521, 1-47.

21. Morimoto, S.; Komatsu, K.; Taura, F.; Shoyama, Y. J. Nat. Prod. 1997, 60, 854-857.

22. Sirikantaramas, S.; Morimoto, S.; Shoyama, Y.; Ishikawa, Y.; Wada, Y.; Shoyama, Y.; Taura, F. J. Biol. Chem. 2004, 279, 39767-39774.

23. Shoyama, Y.; Tamada, T.; Kurihara, K.; Takeuchi, A.; Taura, F.; Arai, S.; Blaber, M.; Shoyama, Y.; Morimoto, S.; Kuroki, R. $J$. Mol. Biol. 2012, 423, 96-105.

24. O'Connor, S. E.; Maresh, J. J. Nat. Prod. Rep. 2006, 23, 532-547. 


\section{Graphical Abstract}

To create your abstract, type over the instructions in the template box below.

Fonts or abstract dimensions should not be changed or altered.

\section{Determination of the absolute configuration}

of the novel anti-trypanosomal iridoid

molucidin isolated from Morinda lucida by

$\mathrm{X}$-ray analysis

Satoru Karasawa, Kenji Yoza, Nguyen Huu Tung, Takuhiro Uto, Osamu Morinaga, Mitsuko Suzuki, Kofi D. Kwofie, Michael Amoa-Bosompem, Daniel A. Boakye, Irene Ayi, Richard Adegle, Maxwell Sakyiamah, Frederick Ayertey, Frederic Aboagye, Alfred A. Appiah, Kofi B-A Owusu, Isaac Tuffour, Philip Atchoglo, Kwadwo K. Frempong, William K. Anyan, Regina Appiah-Opong, Alexander K. Nyarko, Taizo Yamashita, Yasuchika Yamaguchi, Dominic Edoh, Kwadwo Koram, Shoji Yamaoka, Nobuo Ohta, Yukihiro Shoyama

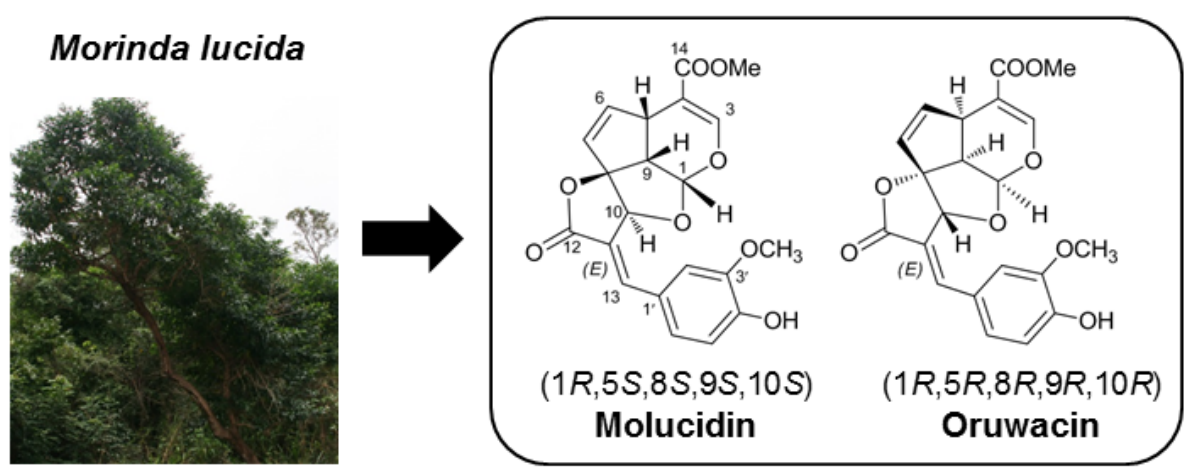

